\title{
Turbulent Flow Measurements near the Discharge Port of a Screw Compressor
}

\author{
J. M. Nouri ${ }^{1}$ (D) D. Guerrato ${ }^{2} \cdot$ N. Stosic ${ }^{1}$
}

Received: 19 March 2019 / Accepted: 1 October 2019 / Published online: 5 November 2019

(C) The Author(s) 2019

\begin{abstract}
Mean flow and turbulence characteristics have been measured within the male and female rotors close to the discharge port of a double screw compressor at different radial positions, two axial positions from the exit port, $\mathrm{H}_{\mathrm{p}}$, and two radial planes, $\alpha_{\mathrm{p}}$. Cycle-resolved axial and tangential mean flow measurements and their corresponding turbulent velocity fluctuations were made over a time window of $1^{\circ}$ using a laser Doppler velocimetry, LDV, system. Measurements were performed through two transparent windows near the inlet of the discharge port inside the male and female working chambers. The results revealed a highly complex 3-D flow within the male and female working chambers, in particular, near the discharge port with two distinct flow zones 1 and 2 before and after the opening of the port, respectively. The flow in zone 1 was controlled by the rotor motion while in zone 2 was greatly influenced by the discharge process. In zone 2 , both components of mean velocities were subjected to a sudden increase in velocity forming strong axial and tangential jet flows due to rapid change in pressure across the port as the flow is exposed into the discharge port. It was found that the flow structures have been affected considerably by the position of the discharge port, radial planes and radial positions. Axial and tangential RMS velocity distributions within both rotors were found to be relatively high and less affected by the flow changes of zones 1 and 2 with almost uniform distribution. The measured magnitudes of axial and tangential RMS velocities suggest it would be reasonable to assume the local turbulence to be isotropic for the modelling purposes. To authors' knowledge, the results are unique, original and in great details not only to describe the flow structure, but also, they can be used in CFD codes to establish a reliable model of the flow and pressure distribution within twin screw machines.
\end{abstract}

Keywords Screw optical compressor · Laser Doppler Velocimetry · Cycle-resolved averaging · Turbulent flows · Mean and RMS velocities

J. M. Nouri

j.m.nouri@city.ac.uk

1 Department of Mechanical Engineering and Aeronautics, City, University of London, EC1V OHB, London, UK

2 Delphi Diesel System, Courteney Rd, Gillingham, Kent ME8 0RU, UK 


\section{Introduction}

Screw compressors could be characterised with their simple arrangement and compact design, high rotational speed and high efficiency over a wide range of speeds and pressure differences, which make them suitable for many industrial applications. Their use nowadays is widespread since they have replaced the traditional reciprocating compressor. Screw compressors are used commonly in a large range of applications such as air compression, refrigerant compression, fuel cell and turbo charging for the automotive industry and many others like building industry, food process, pharmaceutical, chemical industry, metallurgical industry and pneumatic transport. At present, they constitute a large percentage of all positive displacement compressors that are sold and currently in operation. The main reason for this success is the development of new rotor profiles and advanced machine tool, which can manufacture the rather complex rotor shape, to tolerances of the order of $3 \mu \mathrm{m}$ at an acceptable cost [1]. Improvements in screw compressors are continually sought-after, in order to increase their performance, reduce their energy consumption, noise generation and manufacturing costs. A screw compressor consists of two rotors, male and the female, contained in a casing with no valves and their meshing lobes form a series of working chambers within which compression takes place as described in [1-3]. As the rotors turn, air is admitted through the space between the rotor lobes and the suction port. Further rotation of the rotors lead to a cut-off of the suction port and the trapped air is pushed forward axially and circumferentially towards the discharge port by the action of the screw rotors; during this period the trapped volume in each passage is reduced and its pressure is increased. This process continues until the working volume between the rotors is exposed to the discharge port allowing gas at high pressure to flow out [2, 3]. Flow leakages through clearances and tolerances take place across several lines like the contact between the two rotors, the sealing between the rotors' tip and the casing, and the clearance between the rotor end face at the discharge end plate.

The entire flow process and, in particular, the leakages play an important role in the compressor performance. It is thus essential to have a good understanding of the gas flow motion in the compressor by quantifying the velocity field in the compressor elements, suction, discharge and working chambers and, especially, through the clearance gaps (if possible) so as to characterize the whole sequence of processes that occur within the compressor. The total number of papers published on the flow characteristics within twin-screw compressors is rather small compared to published work on other machines such as turbochargers and pumps. Moreover, the investigations of [4-7] seem to be the only reported experimental works on the flow behaviour in screw compressors or screw superchargers who have reported the axial mean and RMS velocities within the working chamber of the male rotor only at one radial plane of $\alpha_{p}=27^{\circ}$ using LDV system. They have reported that the chamber-to-chamber (cyclic) flow variations were negligible and the flow velocities of all five working chambers were very similar. They also reported that the axial flow distribution across the working chamber of male rotor were separated in three zones 1, 2 and 3 controlled by the rotor motion, by the discharge process and by the flow leakage near the tip, respectively. The present research work is the continuation of the works of [4-7] and it is intended to complete the mapping of the flow on the same screw compressor for both male and female working chambers. The velocity field measurements are also expanded to include both axial and tangential mean and RMS velocity characteristics at different radial planes $\left(\alpha_{p}=17^{\circ}\right.$ and $\left.37^{\circ}\right)$ that were reported by [4-7]. Thus, to the authors' knowledge, the presented results in this report are unique contribution and not available in the open literature. However, there are many experiments focusing on the 
performance of the compressors and CFD calculations; for example, [8-10] describe some performance test measurements in the same compressor used for this experiment where properties of other parameters in the compressor, such as the suction and discharge pressures and temperatures have been measured with standard laboratory-type instruments and compared with predicted values from an existing CFD model, which allowed the validation and further development of the CFD [11-13] package. In addition, [14-16] reported theoretical and experimental studies on screw compressors and made transient thermal analysis, numerical simulation and experimental verification. Presented a procedure to determine empirical constants in a 'training process' which optimises multiple constants using a range of test cases. $[14,16]$ presented models that after proper calibration gave good agreement between simulated and measured results, while [15] showed that thermal deformation is accounted for by complex $3 \mathrm{D}$ FEA or CFD calculations when the nominal design clearances is corrected with the measured correction factors.

The material presented in this paper is part of a long-term research project attempting to measure the fluid mean velocity distribution and the corresponding turbulence fluctuations at various cross-sections within the working chambers of the male and female rotors to characterise the mean and turbulent flow development through the compressor at different phase angles. The overall aim is to reveal how major features of the fluid flow within the machine are affected by the rotor geometry and operating conditions. Flow in screw compressors is complex, three-dimensional and strongly time-dependent as already indicated by the results of [4-7] and are similar in flow complexity to the in-cylinder flows of IC engines [17, 18], centrifugal pumps [19] or in turbocharge turbines [20-22] and mixing reactors [23]. This implies that the measuring instrumentation must be robust to withstand the unsteady aerodynamic forces, have high spatial and temporal resolutions and, most important, must not disturb the flow. Only the optical diagnostics like LDV and PIV [3] can fulfil these requirements, in particular, resolving the turbulent flow characteristics with LDV as successfully demonstrated by previous research in similar complex flows of [17-23].

The preferred method of research is characterisation of the fluid mean velocity and turbulence fluctuations at a range of pre-selected measurement points using a dual beam Laser-Doppler Velocimetry (LDV). Angle-resolved of axial and tangential mean and RMS velocities have been obtained inside the working chambers of the male and female rotors. Measurements were performed in the interlobe region near the discharge port by passing the laser beam through purposed built transparent windows, made of Plexiglas (Perspex), that were installed on a grove machined on the compressor casing; more details will be given in the following section. The results will be presented and discussed in the subsequent section and the reports will end with a summary of the main findings.

\section{Flow Configuration and Instrumentations}

Velocity measurements were obtained in a standard screw compressor, with ' $\mathrm{N}$ ' type rotor profiles and a 5/6-lobe configuration, using LDV technique. The rotors' outer diameters are respectively $128 \mathrm{~mm}$ for the male and $101 \mathrm{~mm}$ for the female rotor and their centre lines are at a distance of $90 \mathrm{~mm}$; the rotor length to diameter ratio is 1.66 . This compressor working conditions would normally comprise a shaft speed range of 1000-5000 rpm and a discharge pressure range of 6-9 bar. A schematic of the compressor rig is shown in Fig. 1(a) which includes a $75 \mathrm{~kW}$ electrical motor that drives the compressor through a six-band belt system 
with a speed ratio of 2.52:1. Since compressor is a flooded type, oil and air are mixed together inside the machine and then the oil is removed from the air by a separator after the discharge. The separated oil is then recycled back into the compressor, via a water-cooled heat exchanger. The separated discharge air is then passed through an orifice plate, in order to determine its flow rate and then exhausted out. The test rig was modified to accommodate the new optical compressor, the transmitting and collecting optics, their traverses and other instrumentations as shown in Fig. 1(b). A Dual beam Laser-Doppler Velocimeter (LDV) was employed operating in the near backscatter mode and comprised a $700 \mathrm{~mW}$ argon-Ion laser at $488 \mathrm{~nm}$ wavelength, a TSI data processor unit, a diffraction-grating unit to divide the light beam into two equal intensity beams and to provide frequency shift; the two beams were then formed the control volume after going through the collimating and focusing lenses.

A fibre optic was used to direct the laser beam from the laser head to the transmitting optics, and a mirror was used to direct the beams from transmitting optics into the compressor through the transparent windows. The collecting optics was positioned around 20 to $25^{\circ}$ to the full backscatter position and comprised collimating and focusing lenses, a $100 \mu \mathrm{m}$ pin hole and a photomultiplier equipped with an amplifier. The size of the pinhole defines the effective length of the measuring volume and its diameter and fringe spacing were calculated to be $79 \mu \mathrm{m}$ and $43.3 \mu \mathrm{m}$. The signal from photomultiplier was processed by a TSI processor interfaced to a PC and led to angle-averaged values of the mean and RMS velocities. In order to synchronise the velocity measurements with respect to the location of the rotors a shaft encoder that provides one pulse per revolution and 3600 train pulses. Instantaneous velocity measurements were made over thousands of shaft rotations to provide sufficient number of samples. In the present study the total number of collected data varied according to the different radial location of the control volume, but on average the sample density was about 1300 samples per shaft degree. Since the TSI software is provided by 4 external channels, one of them was used to collect the pressure information from a pressure transducer equipped with an amplifier. The pressure samples were collected simultaneously with the incoming velocity and instantaneous position of the shaft; these results together with effect of temperature and rotor speed were presented in [5] and will not be repeated here. Also see [3] for full details on LDV technique, beams orientation for male and female rotors, selection of the optical windows, and the data processing. The transparent window for optical access into the rotors chamber were machined from acrylic to the exact internal profile as the rotors casing and were positioned at the pressure side of the compressor $14 \mathrm{~mm}$ away from the end of the rotors or the discharge port; the final

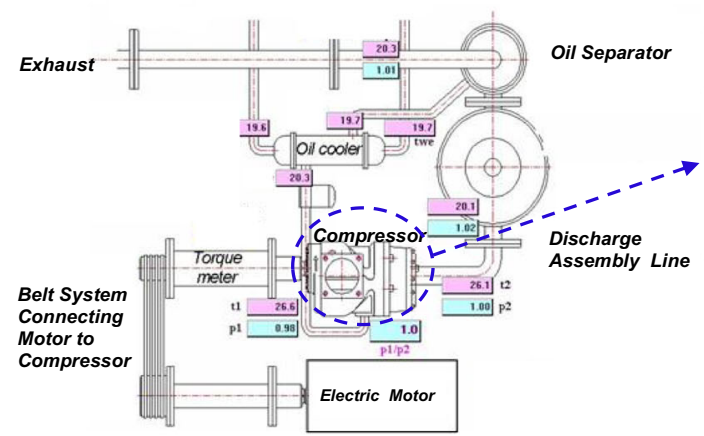

(a)

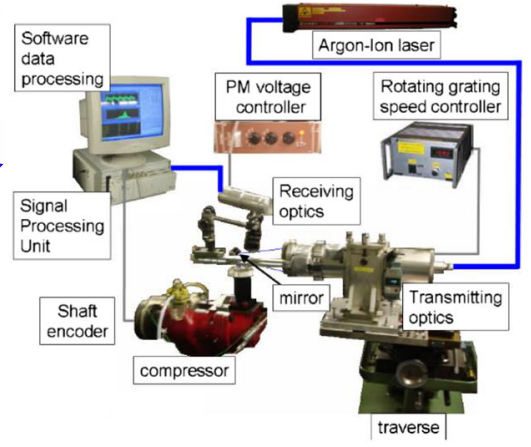

(b)

Fig. 1 Compressor rig: (a) Schematic representation; (b) LDV Set up and instrumentation of the compressor 
design of the window is shown in Fig. 2(a). After machining the internal and external surfaces of the window, it was fully polished to allow optical access. An opening was made on the top of the compressor casing near the discharge port to house the window with $20 \mathrm{~mm}$ width as shown in Figs. 2(b) together with LDV transmitting and collecting optics. This opening is purposely situated in this location to give a good access to interlobe region near the discharge port and allowed flow measurements by LDV within both male and female working chambers where the flows merge and interact with each other before exiting into the discharge port.

Inside the compressor, angle-resolved axial velocity measurements were made along several radial planes inside the working chambers of the rotors near the discharge port. The radial planes are defined by their angles, $\alpha_{\mathrm{p}}$, to the vertical planes through the male and female rotors' center lines as shown in Fig. 2(c) and Figs. 3 (a) and (b). Figure 3 also shows the coordinate systems applied to each rotor with $\mathrm{R}_{\mathrm{p}}$ being radial positions of the control volume (also see fig. 2(c)) and $\mathrm{H}_{\mathrm{p}}$ is the distance of the control volume from end of the rotors or the discharge port location. For both rotors, three angular planes of $\alpha_{p}=17^{\circ}, 27^{\circ}$ and $37^{\circ}$ (with an uncertainty of $\pm 0.25^{\circ}$ from the LDV tilting table) were selected according to Figs. 2(c) and 3; note that measurements beyond $\alpha_{p}=37^{\circ}$ would not be possible as the laser beams were interfering with bottom edge of window. With this arrangement, the flows within the male and female chambers at measuring planes at $\alpha_{\mathrm{p}}=37^{\circ}$ are the nearest to each other while at $\alpha_{\mathrm{p}}=17^{\circ}$ they are the furthest apart within the combined working chamber, this suggests more interaction of the two flows at $\alpha_{\mathrm{p}}=37^{\circ}$. Measurements were made at different radial location, $\mathrm{R}_{\mathrm{p}}$, from the root of the rotors to their tips, i.e. from 44 to $63.2 \mathrm{~mm}$ for the male rotor and 38 to $50 \mathrm{~mm}$ for the female rotor. The axial planes, $\mathrm{Hp}$, at which the measurements were made varied from 20 to $34 \mathrm{~mm}$ from the discharge port; it is defined as the distance between the measuring point to the discharge port (or end of rotos) as shown in Fig. 3. It should be noted that in this paper only new data at $\alpha_{p}=17^{\circ}$ and $\alpha_{p}=37^{\circ}$ are presented and discussed; the data at $\alpha_{\mathrm{p}}=27^{\circ}$ will not be presented here as they were presented in the previous reports published by the current authors.

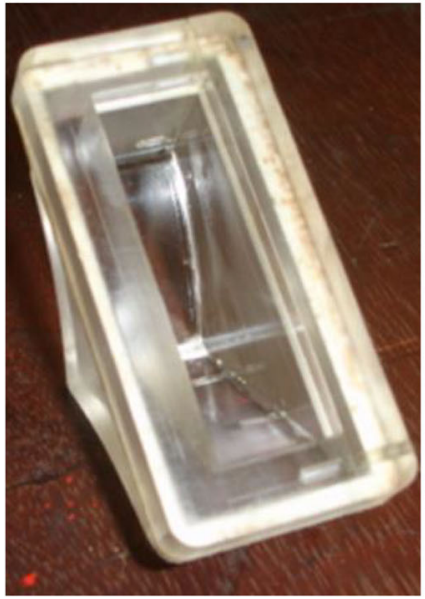

(a)

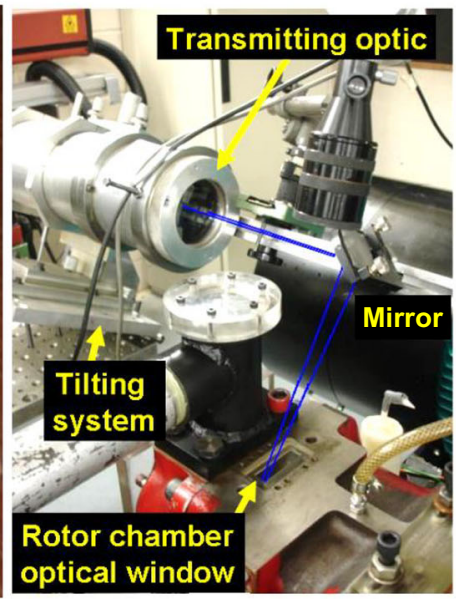

(b)

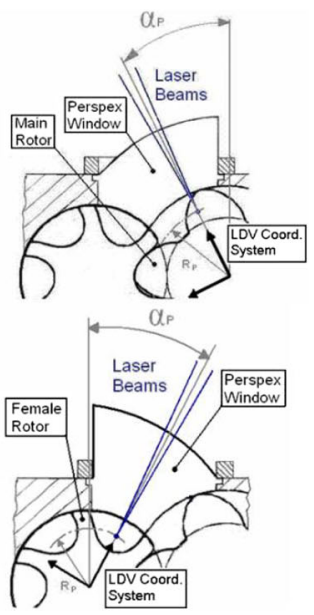

(c)

Fig. 2 Optical compressor set up: (a) Transparent window; (b) Modified optical compressor with transparent window near the discharge port plus the optical setup; (c) 2-D optical Coordinate system with $\alpha_{p}$ and $R_{p}$ definitions viewed from the rotors' side 

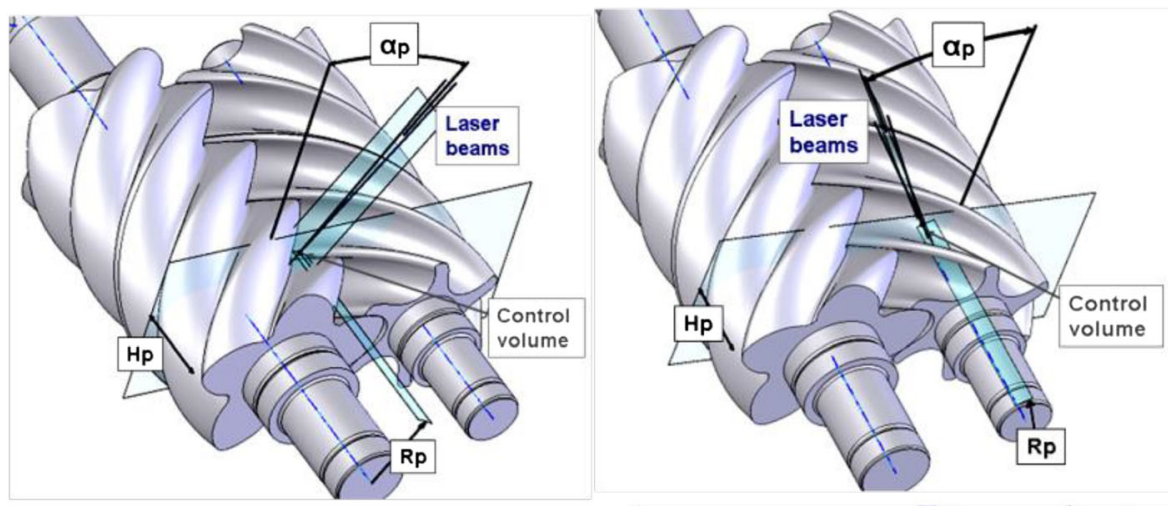

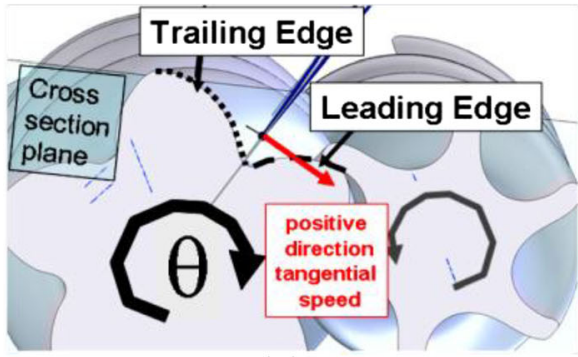

(a)

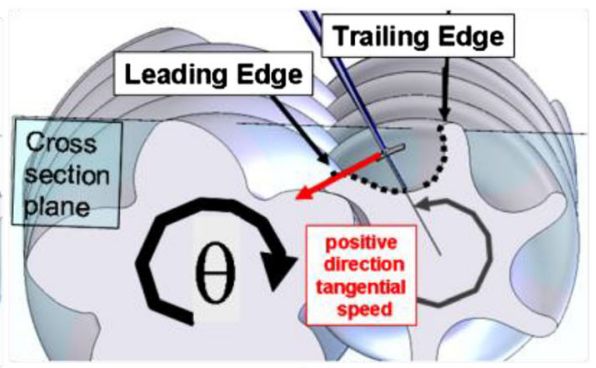

(b)

Fig. 3 3-D Coordinate system adopted for the rotor chambers: (a) male rotor working chamber cross-section (CS); (b) female rotor working chamber CS viewed from discharge port's side. The trailing and leading edges definition for the rotors are also shown

The desired LDV measurements within the compressor under oil flooded (for cooling purposes) conditions were not possible due to sever and continuous fouling of the optical window as explained in [5-7]. Thus, in order to be able to measure the velocity field, it was decided to run the compressor with no oil injection at a speed of $1000 \mathrm{rpm}$ with outlet and inlet pressure ratio $1: 1$ and a discharge temperature of $55 \pm 3{ }^{\circ} \mathrm{C}$. Despite this unusual working condition, the internal compression ensures a flow structure similar to the one occurring in normal operating conditions. The flow regime was identified by the Reynolds number defined as $R e=\rho V_{p} D_{p} / \mu$ where $\rho$ and $\mu$ are air density and dynamic viscosity, respectively, where $\mathrm{V}_{\mathrm{p}}$ is the male rotor pitch axial velocity defined as the axial speed at which a single working chamber travels from the suction to the discharge port of the compressor and is given by $V_{p}=\omega D_{p} \tan \beta / 2$ where $\omega=2 \pi N / 60, \mathrm{D}_{\mathrm{p}}$ is the male rotor pitch diameter and, $\beta$ is the pitch angle. $V_{p}$ was calculated to be $3.95 \mathrm{~m} / \mathrm{s}$ for a rotor speed, $\mathrm{N}$, of $1000 \mathrm{rpm}$, pitch diameter of $81.8 \mathrm{~mm}$ and pitch angle of $42.73^{\circ}$. The average Reynolds number was found to be 17,700 and therefore the flow can be considered to be turbulent; this is based on consideration of an axial flow through the working chamber to be similar to that of a typical helical duct flow, and that all angled-resolved (over a $1^{\circ}$ ) velocity measurements clearly indicated that the flow is turbulent. The volumetric flow rates through the compressor were measured by an orifice plate installed in the exhaust pipe and it was $1.05 \mathrm{~m}^{3} / \mathrm{min}$. The speed was obtained with an optical shaft encoder which was fixed at the end of the driving shaft with 3600 train pulses per revolution providing an angular resolution of 0.1 degrees. With this arrangement, the male rotor was rotating clockwise and the female anticlockwise as shown in Fig. 3. 
The air flow was seeded by a silicone oil atomiser capable of producing droplet sizes in the range of 1 to $2 \mu \mathrm{m}$; a low viscosity silicone oil of $5 \mathrm{cSt}$ was used. A Matlab program was written in which the information of the shaft angular position from the shaft encoder was used to resolve the velocity with respect to the rotors' angular position, the so-called 'gated' measurements. This has been done by collecting the sum of all the instantaneous velocities over a given time-window and then the ensemble mean and RMS values were calculated. This method of gated measurements proved to be efficient since the data was collected continuously over the entire $360^{\circ}$ cycle as the rotor turned, and provided ensemble averages for every one degree $\left(\Delta \theta=1^{\circ}\right)$ time-window. The total measuring time for each point was about $25 \mathrm{~min}$ which, apart from a few critical points, gave a minimum number of 700 samples per timewindow corresponding to statistical uncertainties of less than $1.7 \%$ and $5.5 \%$ in the ensemble mean and RMS velocities, respectively, based on a $95 \%$ confidence level and velocity fluctuations of the order of $20 \%$ of the mean value. The direction of the measured axial velocity component is along the axes of the rotor with positive value towards the discharge port. For tangential velocity measurement, the optical set up provided a positive value in the clockwise direction.

Figures 4 (a) and (b) show the discharge port flow geometry and its actual port boundaries, which is situated at the end of the pressure side of the compressor casing, while Figs. 4 (c), (d) and (e) depict schematically the port boundaries as the flow components from the male and female working chambers interact and pass through the port. This is important since it helps to explain the measured flow variation within the working chambers of the male and female rotors in the interlobe region upstream of the discharge port. From images of Figs. 4(a) and (b), it is clearly evident that discharge port cross-section at the rotor's side is very different from that at the cavity (discharge) side; that influences greatly the flow conversion through the port. The discharge port has been machined in the compressor casing at a fixed location in the pressure side next to the end faces of the rotors. It should be mentioned that he opening and closing of the port it not a sudden operation. It is rather a gradual opening and closing depending on the angular positions of the rotos when their end face working chamber or solid blade come in contact with the discharge port, and thus the flow exposed area varies as the $\theta$ changes. On the rotor's side, the opening of the port cavity is shaped like a reversed double delta, referred to as the $\mathrm{W}$-section, to accommodate and streamline the flow coming from the both working chambers of male and female rotors as shown in Fig. 4(a). The crosssection of the port reduces as the flow moves from rotor side into the discharge cavity side so that at the port exit the opening forms a single inverted delta shape, Fig. 4(a\&b), and will be referred to as the $\mathrm{V}$-section. In addition, as mentioned above, due to the relative position of the rotors with respect to the discharge port, the actual exposed flow area through which the mass fluid flow passes from rotors' chambers to the discharge port is different at different rotors' angular positions, $\theta$, and it is highlighted in purple colour schematically in Figs. 4(d) and (e) as an example. These regions are referred to as exposed-areas (chambers A and B) and are always smaller than physical port crosssection area due to the changes in rotors angular positions, which can be considerable at some particular rotor positions like that in Fig. 4(e); chambers A and B are referred to areas bounded between the two rotor blades and the discharge port boundary. This can have considerable consequences on the velocity distribution within the working chambers upstream of the discharge port, and also on the discharge cavity flow particularly near the exit of the discharge port, Fig. 4(c). In addition, the relative position of the radial planes, $\alpha_{\mathrm{p}}$, for both rotors with the $\mathrm{W}$-section port suggest that the flows with both rotors at $\alpha_{\mathrm{p}}=37^{\circ}$ (nearest to each other) are more exposed to W-section port opening than those at $\alpha_{\mathrm{p}}=17^{\circ}$ (furthest away); this was evident from velocity results that are presented and discussed below in the results section. 


\section{Results and Discussion}

The post processing technique and the choice of the most suitable resolved angle ( $\Delta \theta$, or timewindow) was already defined in dtails by $[3,6]$, as well as the overlapping procedure involved in the generation of the mean and RMS velocity profiles; a representation of an averaging method is shown in Fig. 5. A purposely written Matlab program used rotors' angular positions, $\theta$, data from a shaft encoder to resolve the velocity with respect to $\theta$ by collecting the sum of the all instantaneous velocities over a given time-window $\left(\Delta \theta=1^{\circ}\right)$ and then calculating the ensemble mean and RMS velocities as shown in Fig. 5. Although $\Delta \theta=2^{\circ}$ was found to be sufficient to represent the mean flow, but in this experiment $\Delta \theta=1^{\circ}$ was chosen in order to minimise uncertainties in RMS measurements due to any mean flow broadening. A second program was written to calculate the locations of the measuring volume in the compressor by considering the effects of light beams reflection and refraction as they pass through the transparent windows.

The following results are a sample of data obtained in this experiment and show the behaviour of the mean axial (U) and tangential (W) components of velocity and the corresponding turbulence $(u \& w)$ as a function of the shaft angular position, $\theta$, for both rotors. Each Figure compares the velocities of male and female rotors at a given axial location $\left(\mathrm{H}_{\mathrm{p}}\right)$, different radial positions $\left(\mathrm{R}_{\mathrm{p}}\right)$ and at two radial planes, $\alpha_{\mathrm{p}}$, of $17^{\circ}$ and $37^{\circ}$. The axial mean velocities are presented first and followed by the tangential mean velocities; the corresponding RMS velocity components will then be presented. The zero shaft angular position, $\theta$, referes to the opening of the discharge port and is the same for male and female rotors as it opens simultaneously for both rotors but, as mention above, the opening cross-section area can be

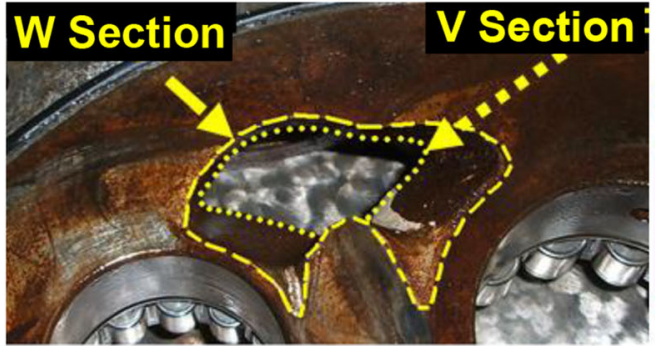

(a)

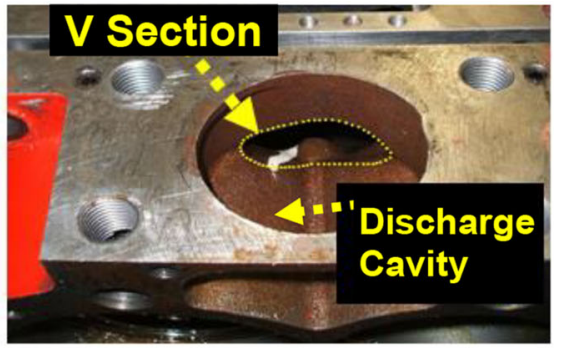

(b)

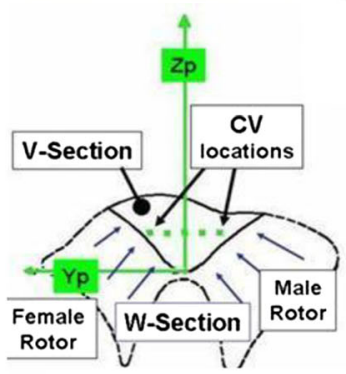

(c)

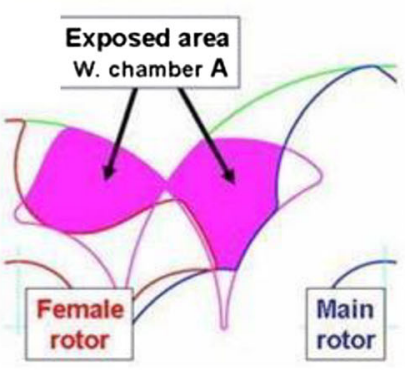

(d)

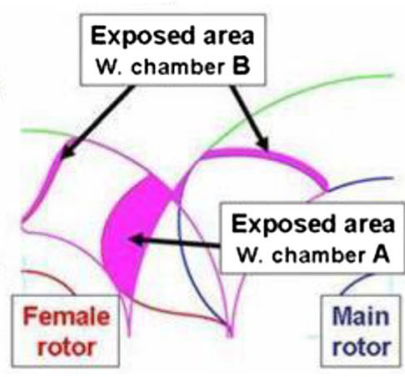

(e)

Fig. 4 Discharge port flow geometry: (a) \& (b) actual discharge port viewed from rotors side (W-section) and discharge cavity side (V-section.); (c) transverse-section of discharge chamber; (d)\&(e) relative positions of rotors with discharge port viewed from rotor side 


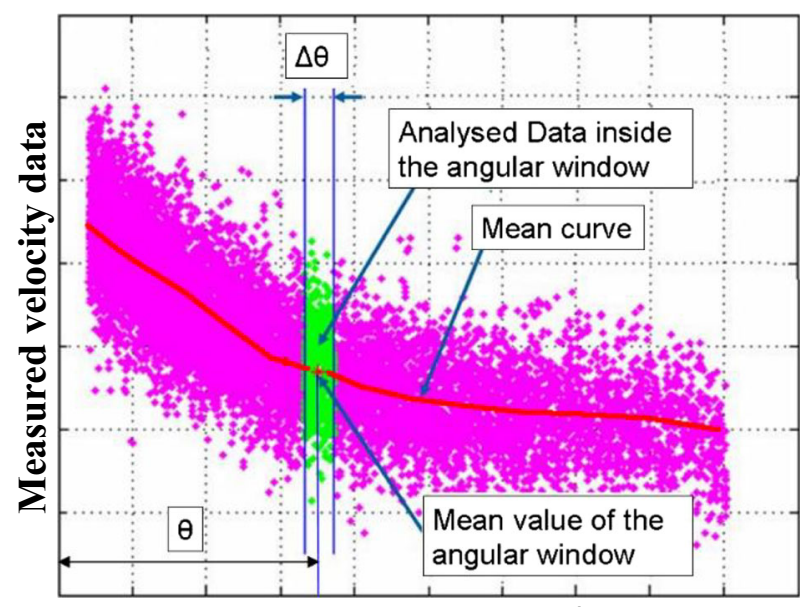

Shaft angular position, $\theta$.

Fig. 5 Representation of angled-window resolution for averaging mean and RMS velocities

different due to relative rotors' position and different cross-section profiles of the rotors. Another feature to be noted is the position of the trailing edge (TE) and leading edge (LE) of the rotors' blade which are identified in Fig. 6 only and would be the same for all other Figures. Also, the list of symboles used to identify the radial positions, $R_{p}$, for male and female rotors will only be given in Fig. 6(a) since these radial locations would be the same on all other Figures. For reference, the pitch velocity or the working chamber travelling speed (WS) calculated above as $\mathrm{V}_{\mathrm{p}}=3.95 \mathrm{~m} / \mathrm{s}$ for a rotor speed of $1000 \mathrm{rpm}$, is also plotted in all mean and RMS velocity plots as a bold blue line and labell as W.S. in Fig. 6(a).

\subsection{Mean Flow Velocities}

Figure 6 compares mean axial flow variations inside the working chamber of the male (left column) and Female (right column) with rotors' angular positions, $\theta$, at a distance $\mathrm{H}_{\mathrm{p}}=34 \mathrm{~mm}$ from discharge port, along two radial planes $\alpha_{p}=17^{\circ}$ and $37^{\circ}$, at different radial locations, $R_{p}$, from near the root of the rotors up to their tips, and for a speed of $1000 \mathrm{rpm}$. The axial flow variations within the working chamber of the male rotor at $\alpha_{p}=27^{\circ}$ were presented and described by [4-7] and only a summary is given here. First, the chamber-to-chamber (cyclic) flow variations were established and the results showed that the axial mean and RMS velocities of all five working chambers were very similar with small differences near the leading edge of the rotor. The axial velocity distribution across the working chamber could be described by dividing the working chamber into three different zones. The first zone was in between the LE and the opening of the discharge port, $\theta=0^{\circ}$, where the flow was controlled by the rotor motion with velocity profiles showing a gradual decrease towards $\theta=0^{\circ}$; the results also showed that at lower $\mathrm{R}_{\mathrm{p}}$ (close to the root of the chamber) the velocities across the chamber were generally lower and became highest at higher $\mathrm{R}_{\mathrm{p}}$, near the tip. The second zone was when the flow was exposed to the discharge port after $\theta=0$ and was influenced by the discharge process and relative position of the of the port's exposed-area. The third zone was restricted to the vicinity of the LE near the tip, where the flow is influenced mainly by flow leakage between two adjacent working chambers and is generally characterised by high 


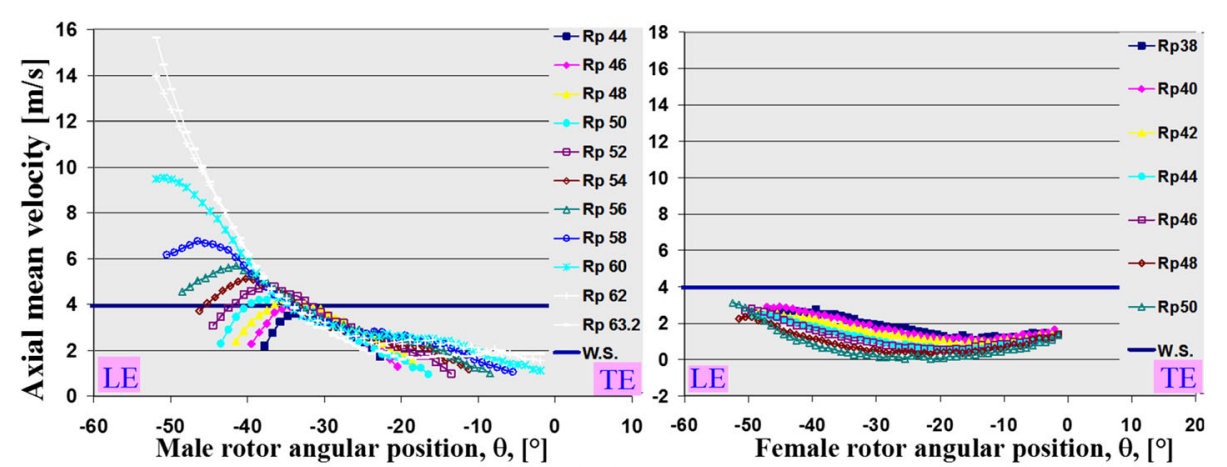

(a) $\alpha_{p}=17^{\circ}$
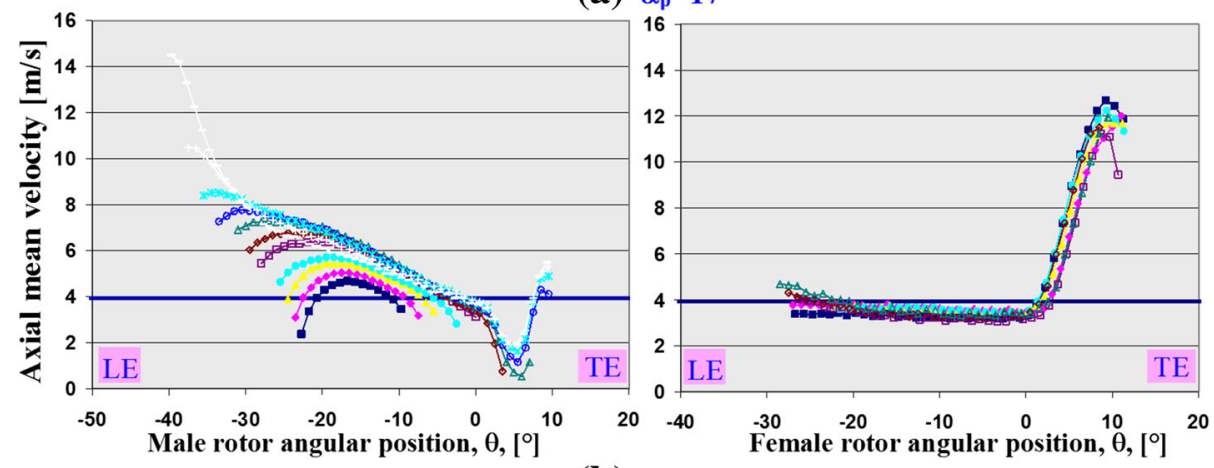

(b) $\alpha_{p}=37^{\circ}$

Fig. 6 Axial mean velocity distribution as a function of angular position, $\theta$, within the male (left column) and female (right column) rotors at different radial positions, $R_{p}$, and at $H_{p}=34 \mathrm{~mm}$ : (a) $\alpha_{p}=17^{\circ}$; (b) $\alpha_{p}=37^{\circ}$

velocity. All these will be reassessed when discussing the axial and tangential flow at radial planes of $\alpha_{p}=17^{\circ}$ and $37^{\circ}$.

The male axial mean flow variation across the working chamber (left column) clearly shows the presence of all these 3 zones for both radial planes of $\alpha_{p}=17^{\circ}$ and $37^{\circ}$ with an exception that zone 2 is almost absent in the case of $\alpha_{\mathrm{p}}=17^{\circ}$, which suggests that the flow is not yet exposed to discharge port at this radial plane due to physical position of the port which is situated in the central part of the interlobe region covering larger radial planes $\left(\alpha_{\mathrm{p}}\right)$ and at larger $\mathrm{R}_{\mathrm{p}}$; the latter also explains the absence of the zone 2 flow characteristics near the root of the male rotor and lower mean velocity values there. It is also evident from the graphs that velocity values at plane $\alpha_{p}=37^{\circ}$ are higher than those at plane $\alpha_{\mathrm{p}}=17^{\circ}$ for the same reason given above and that the angular axial velocity profiles near the root (lowest $R_{p}$ ) is much narrower than those near the tip due to large variation of the internal profile of the male rotor's blade with $\mathrm{R}_{\mathrm{p}}$, see Fig. 3. It is interesting to note that the velocity profile near the root looks almost like a parabola (similar to a duct flow with no slip conditions at blade walls), but as $R_{p}$ increases the velocity values, in general, increases and the profiles spread across the working chamber with the maximum velocity closer to the LE and reducing gradually towards the TE. Another important flow feature for the male rotor is the flow variation in zone 2 after the port opening as is evident in Fig. 6(b) left column. The results show that the velocities continue to decrease up to $\theta \approx 5^{\circ}$ but by a faster rate than before the opening of the port, and then they increase rapidly towards the TE. The initial decrease indicates the presence of an adverse pressure gradient downstream as the port opening hasn't exposed to this radial plane yet, while 
the flow at $\theta \approx 5^{\circ}$ starts to sense the exposed area of the port with large pressure difference across the port and therefore rapid increase in velocity. In Zone 3, the axial flow velocities are highest in the vicinity of the $L E$ near the rotor tip (for $R_{p}>60 \mathrm{~mm}$ ). This is mainly due to the flow leakage between two adjacent working chambers. Since the rotors have a helical shape then the leakage flow on the male rotor as it enters into the next chamber would have strong axial and tangential components towards the port and tangential directions adding to the axial and angular momentums (or increase in their velocities) within the chamber with its highest impact to be close to LE and near the tip.

The mean axial flow characteristics within the female rotor working chamber (right column) of Fig. 6 show clearly the presence of only two distinct zones 1 (from LE to $\theta=$ $0^{\circ}$ ) and 2 (from $\theta=0^{\circ}$ to TE) with no flow leakage (zone 3) detected on the female rotor at both radial planes compared to the male rotor where strong leakage flow was detected. The reason for this may well be due to the different shape of the rotors at the contact point with the compressor casing where with female rotors the blade has almost straight TE and LE profiles normal to the casing (see Fig. 3), while with the male rotors has a strong convex LE and TE profiles forming a convergent divergent flow passage across the contact point, which creates a relatively strong pressure difference across the contact point as the rotor turns and hence promoting the leakage flow. Within the zone 1 , the flow is mainly controlled by the rotor motion, similar to the male rotor, and shows generally uniform angular axial velocity profiles across the working chamber, in particular at $\alpha_{p}=37^{\circ}$; this is in contrast with the male rotor, which may be due to more uniform chamber cross-section area with female rotor than that of male rotor. In the second zone (from $\theta=0^{\circ}$ to TE), the flow is controlled by the discharge process and the results at $\alpha_{\mathrm{p}}=37^{\circ}$ clearly shows the flow is associated with a sudden and rapid flow velocity increase as it is exposed to the opening of the port at $\theta \approx 3^{\circ}$ till very close to TE of the rotor $\left(\theta \approx 10^{\circ}\right)$ where the flow velocity starts to drop near the TE wall as it would be expected. Again, the second flow zone is absent at $\alpha_{p}=17^{\circ}$ because the flow is not yet exposed to the discharge port at this radial plane as explained above. It is interesting to note that the flow velocities at $\alpha_{p}=37^{\circ}$ are almost twice as large as those at $\alpha_{p}=17^{\circ}$ with values similar to that of $\mathrm{V}_{\mathrm{p}}$. Also, unlike the male rotor, the angular axial velocity profiles at different $\mathrm{R}_{\mathrm{p}}$ locations, from the root to near the tip, span over a similar range of $\theta$ due to again the much smaller variation of the internal profile of the two adjacent female rotor's blades with $R_{p}$ compared to that of male rotor, see Fig. 3.

Closer to discharge port at $\mathrm{H}_{\mathrm{p}}=22 \mathrm{~mm}$, the axial mean flow distributions within both male and female chambers are presented in Fig. 7 and show more clearly the presence of all three flow zones within male rotor chamber and the two flow zones within female rotor chamber even at smaller radial plane of $\alpha_{p}=17^{\circ}$. In general, the flow patterns of both rotors are similar to those at $\mathrm{H}_{\mathrm{p}}=34 \mathrm{~mm}$, Fig. 6, with velocity values slightly larger. The results of Figs. 6 and 7 also show that during the period when the flow is influenced by the rotors' motion, zone 1 before $\theta=0^{\circ}$, the axial mean flow within the male working chamber is much stronger than that within the female rotor, while during the period when the flow is dominated by the discharge process, zone 2 after $\theta=0^{\circ}$, the axial mean jet flows within the female working chamber is much higher than those in male rotor; e.g. by more than twofold at both radial planes and $\mathrm{H}_{\mathrm{p}}=$ $22 \mathrm{~mm}$. The latter can be attributed to faster flow exposure with the female rotor into the discharge port due to wider W-Section on female side and more importantly its smaller end cross-section profile relative to that of the male rotor.

Figure 8 compares mean tangential flow variations inside the working chamber of the male (left column) and Female (right column) $34 \mathrm{~mm}$ from the discharge port at $\alpha_{\mathrm{p}}=17^{\circ}$ and $37^{\circ}$ 

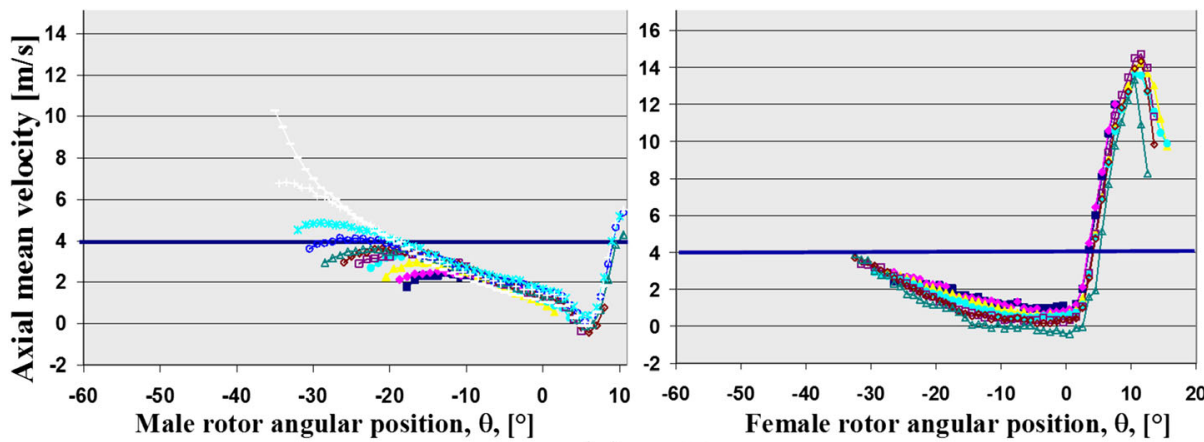

(a) $\alpha_{\mathrm{p}}=17^{\circ}$
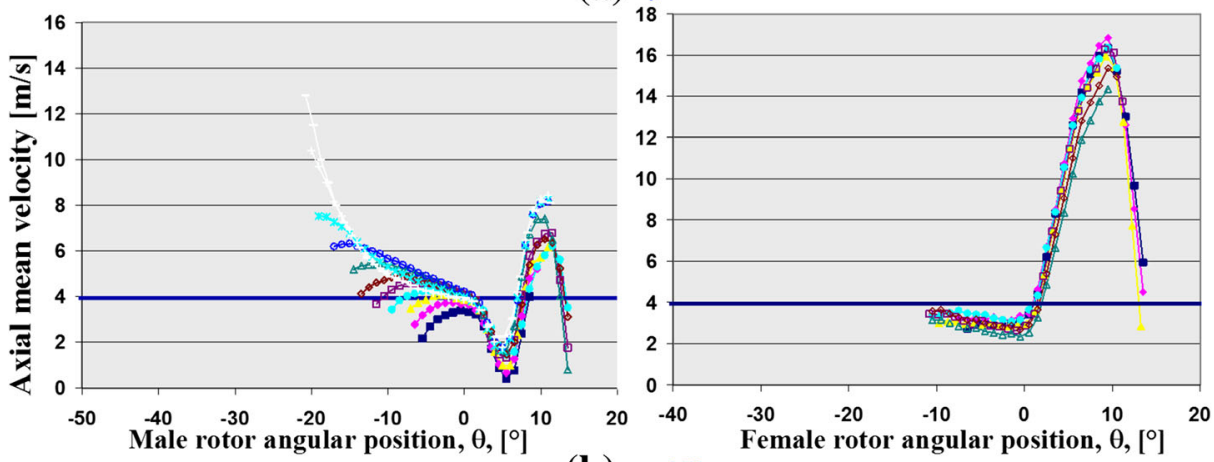

(b) $\alpha_{p}=37^{\circ}$

Fig. 7 Axial mean velocity distribution as a function of angular position, $\theta$, within the male (left column) and female (right column) rotors at different radial positions, $\mathrm{R}_{\mathrm{p}}$, and at $\mathrm{H}_{\mathrm{p}}=22 \mathrm{~mm}$ : (a) $\alpha_{\mathrm{p}}=17^{\circ}$; (b) $\alpha_{\mathrm{p}}=37^{\circ}$

for different radial locations, $\mathrm{R}_{\mathrm{p}}$. As mentioned earlier, the male rotor turns clockwise and female rotor anti-clockwise and the optical set up provided a positive value of tangential velocity in the clockwise direction. The mean tangential flow characteristics can be categorised to the same flow zones as those identified for axial flow. Within the male rotor (left column) working chamber in zone 1 , the results at almost all $\mathrm{R}_{\mathrm{p}}$ (except near the tip) show a decrearse in tangential velocities from LE to a minimum value within the core of the chamber and then increase again towards the opening of the port, $\theta=0^{\circ}$; as expected the mean tangential velocity direction is clockwise in the same direction as the rotor. The angular tangential velocity profile looks like an inverted parabola at all $\mathrm{R}_{\mathrm{p}}$ particularly close to the root of the rotor with minimum velocity around zero value around the core of the chamber; this pattern is opposite to that of parabola axial flow profile with a maximum at the core, which will dominate the flow around the core and causing the reduction in tangential velocity there. Near the tip, $R_{p}=62$ and $63.2 \mathrm{~mm}$, and close to LE, the tangential velocities are high $\left(1\right.$ to $\left.2 \mathrm{~V}_{\mathrm{p}}\right)$ which is a good indication of domination of flow leakage and it is categorised as zone 3 . After the opening of the discharge port, $\theta=0^{\circ}$ (Fig. 8(b) left), the results for the radial plane $\alpha_{p}=37^{\circ}$ show a rapid increase in tangential velocity (in the same direction as the male rotor) during the flow exposure to the discharge port forming a jet like flow with a maximum value close to TE and then drop again in the vicinity of the TE wall of the rotor. At smaller radial plane, $\alpha_{p}=17^{\circ}$, the zone 2 flow is absent like in axial flow of Fig. 6(a) due to lack of flow exposure to discharge port at this plane as was explain before. 

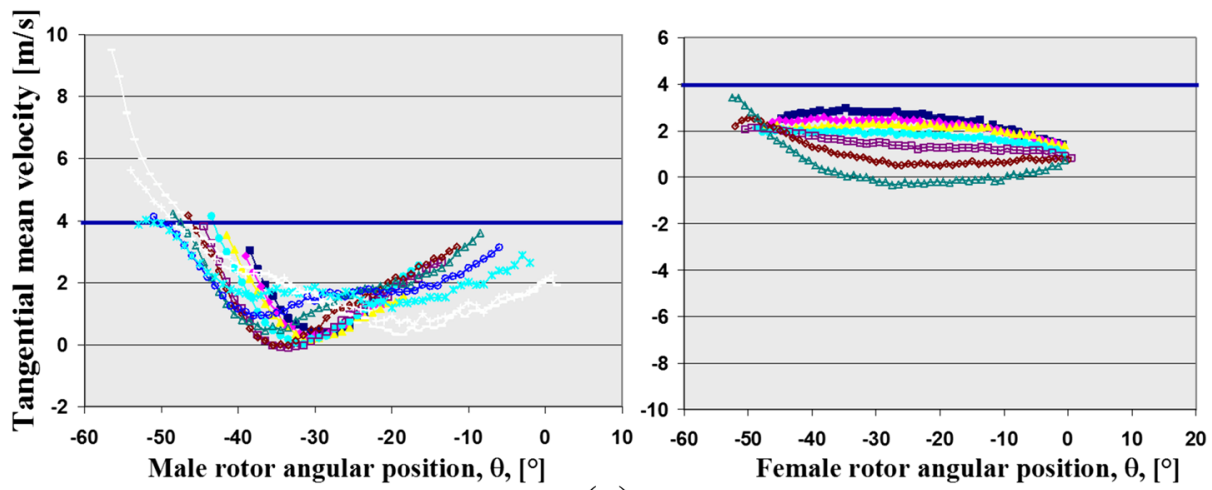

(a) $\alpha_{\mathrm{p}}=17^{\circ}$
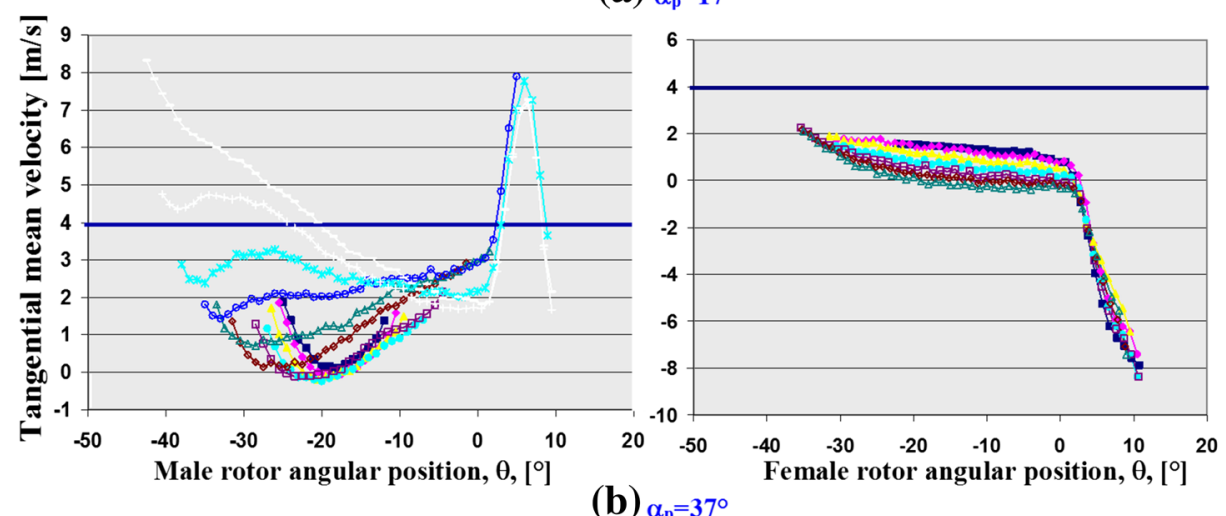

(b) $\alpha_{\mathrm{p}}=37^{\circ}$

Fig. 8 Tangential mean velocity distribution as a function of angular position, $\theta$, within the male (left column) and female (right column) rotors at different radial positions, $\mathrm{R}_{\mathrm{p}}$, and at $\mathrm{H}_{\mathrm{p}}=34 \mathrm{~mm}$ : (a) $\alpha_{\mathrm{p}}=17^{\circ}$; (b) $\alpha_{\mathrm{p}}=37^{\circ}$

The mean tangential flow variations within the female rotor working chamber (right column, Fig. 8) clearly show the presence of the flow zone 1 (from LE to $\theta=0^{\circ}$ ) for both radial planes of $\alpha_{p}=17^{\circ}$ and $37^{\circ}$. In this zone and unlike the male rotor, the velocity profiles at $\alpha_{p}=17^{\circ}$ are fairly uniform with positive (clockwise) values and an average value of order of $0.5 \mathrm{~V}_{\mathrm{p}}$ near the roots of the rotor. As $\mathrm{R}_{\mathrm{p}}$ increases the tangential velocities start to decrease gradually so that near the tip the velocities become negative (anti-clockwise) and of order of $-0.1 \mathrm{~V}_{\mathrm{p}}$; similar pattern can be seen at $\alpha_{\mathrm{p}}=37^{\circ}$ within the zone 1 . The clockwise direction of tangential velocities within the female chamber are unexpected as the rotor is turning anticlockwise and the results suggest the great influence of the male rotor motion (clockwise) with its uniform axial flow (Figs. 6a and 7b) on the tangential flow within the female chamber. This pattern of the tangential flow in zone 1 within the female rotor chamber can also be seen closer to the port (at $\mathrm{H}_{\mathrm{p}}=22 \mathrm{~mm}$, Fig. 9) but more pronounced due to more influence of the port exposure area. In conclusion, the tangential flow pattern in zone 1 within the female rotor looks like a large vortex moving in opposite direction and as mention before may be due to the influence of the much larger male rotor blade motion as they swept through the female rotor' chamber. In zone 2 (from $\theta=0^{\circ}$ to TE), the results at $\alpha_{p}=37^{\circ}$ show that, as soon as the flow is exposed to the port opening, the tangential velocity decrease (or increase in the rotor's direction) sharply to negative (anti-clockwise) values to up to $-2 \mathrm{~V}_{\mathrm{p}}$ near the TE for all radial positions, $\mathrm{R}_{\mathrm{p}}$. This is expected and shows that as soon as a tangential flow undergoes the 
discharge process it will gain angular momentum and follow the female rotor rotation. Again, at smaller radial plane, $\alpha_{\mathrm{p}}=17^{\circ}$, the zone 2 flow is absent, and as mentioned before due to lack of flow exposure to discharge port at this plane. Like with the female axial flow and within the measured range, no clear evidence of the flow leakage (zone 3 ) has been detected within the female rotor compared to the male rotor where strong leakage flow detected for the same reasons given before when axial flow within female rotor was discussed.

Closer to discharge port at $\mathrm{H}_{\mathrm{p}}=22 \mathrm{~mm}$, Fig. 9, tangential mean flow variations within the male and female working chambers show similar, but more pronounced, flow structures to those observed at $\mathrm{H}_{\mathrm{p}}=34 \mathrm{~mm}$ with velocity magnitude slightly larger particularly in zone 1 . Flow structures of zones 1 and 2 are clearly evidence at both radial planes before and after the opening of the discharge port, $\theta=0^{\circ}$, in particular, in zone 2 at $\alpha_{p}=17^{\circ}$ where the influence of the discharge port opening is evidence in formation of an anti-clockwise tanjential flow jet with maximum velocities of values up to $-2 \mathrm{~V}_{\mathrm{p}}$ at all radial positions, $\mathrm{R}_{\mathrm{p}}$.

Figures 6, 7, 8 and 9 clearly show the presence of a complex 3-D mean flow within the male and female near the discharge port and that the opening of the discharge port influence both axial and tangential flow within both rotors as they approach the exposure area of the exit port. To summarise, it can be concluded that, the results obtained for all axial and tangential components, within both male and female rotors' chambers, follow three distinct flow zones 1 , 2 and 3 as described above, and are influenced by the rotors' motions, opening of the discharge
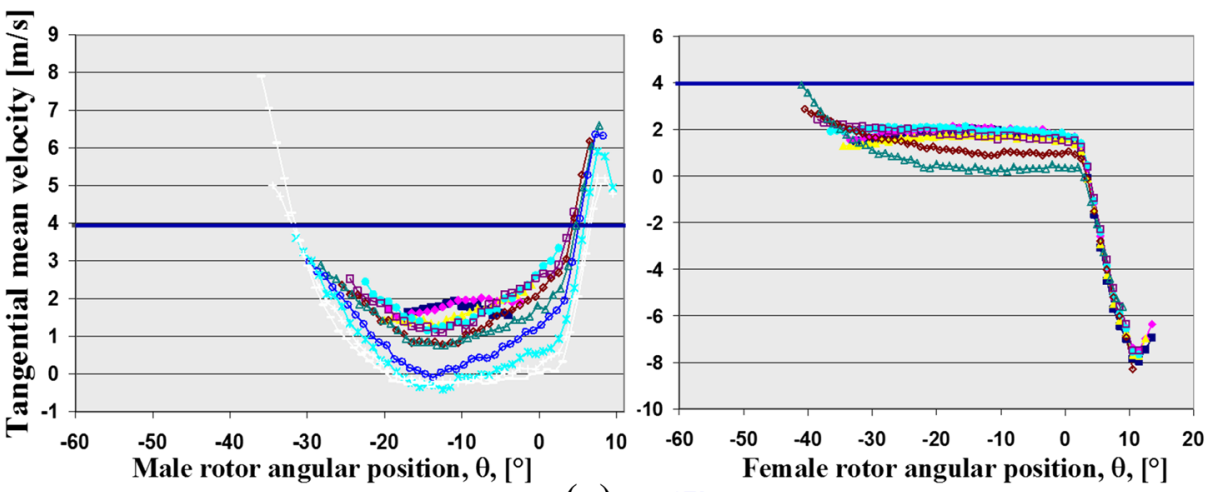

(a) $\alpha_{p}=17^{\circ}$
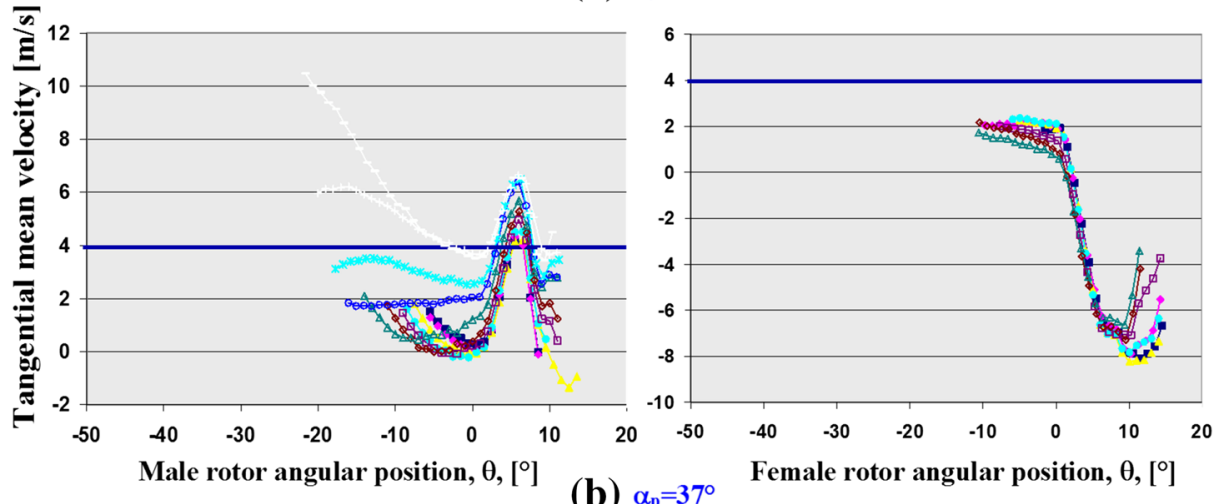

(b) $\alpha_{p}=37^{\circ}$

Fig. 9 Tangential mean velocity distribution as a function of angular position, $\theta$, within the male (left column) and female (right column) rotors at different radial positions, $R_{p}$, and at $H_{p}=22 \mathrm{~mm}$ : (a) $\alpha_{p}=17^{\circ}$; (b) $\alpha_{p}=37^{\circ}$ 
port and the chamber-to-chamber flow leakage, respectively. For the latter flow zone 3, no clear flow leakage was detected for the female rotors.

\subsection{Turbulent Flow Velocity Fluctuations}

Variations of the measured axial and tangential velocity fluctuations are presented in Figs. 10, 11, 13 in the same order as their mean flow variations of Figs. 6, 7, 8, 9. Axial RMS velocity distributions within the male and female working chambers at a distance $34 \mathrm{~mm}$ from the discharge port at two radial planes are presented in Fig. 10 which show almost uniform angular axial RMS velocity profiles for male rotor (left column) with a gradual decrease in RMS values from an average value of $1.75 \mathrm{~m} / \mathrm{s}\left(0.43 \mathrm{~V}_{\mathrm{p}}\right)$ near the $\mathrm{LE}$ to around $1.25 \mathrm{~m} / \mathrm{s}\left(0.3 \mathrm{~V}_{\mathrm{p}}\right)$ close to TE at smaller radial plane $\alpha_{\mathrm{p}}=17^{\circ}$. There is small difference between RMS velocity profiles at different radial positions, $\mathrm{R}_{\mathrm{p}}$, with no particular trend and can be considered to be similar. The corresponding RMS values at $\alpha_{\mathrm{p}}=37^{\circ}$ are smaller but more uniform than those at $\alpha_{p}=17^{\circ}$ with values of $0.37 \mathrm{~V}_{\mathrm{p}}$ and $0.25 \mathrm{~V}_{\mathrm{p}}$ near the LE and TE, respectively. Within the female rotor (right column) the RMS variations exhibit even more uniform distribution both as a function of $\theta$ and $R_{p}$ with an overall average value of around $0.3 \mathrm{~V}_{\mathrm{p}}$ at both $\alpha_{\mathrm{p}}=17^{\circ}$ and $37^{\circ}$; again, like with the male rotor, the distribution of axial RMS at $\alpha_{p}=37^{\circ}$ is more uniform than that at $\alpha_{\mathrm{p}}=17^{\circ}$. The largest RMS velocity value is with the male rotor near the LE close the rotor's tip with a value up to $0.5 \mathrm{~V}_{\mathrm{p}}$. This flow region was referred to as zone 3 where the flow leakage took place and its merge and interaction with the chamber flow resulted in larger mean axial flow variation and hence larger velocity fluctuation or larger RMS values.

Figure 11 presents the axial RMS velocity distributions within the male and female working chambers for radial planes of $\alpha_{p}=17^{\circ}$ and $37^{\circ}$ at $H_{p}=22 \mathrm{~mm}$ closer to the discharge port
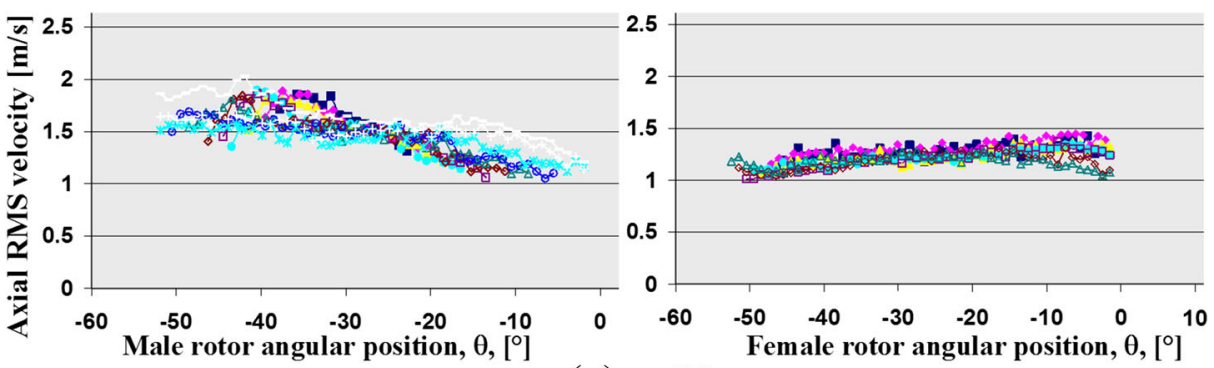

(a) $\alpha_{\mathrm{p}}=17^{\circ}$
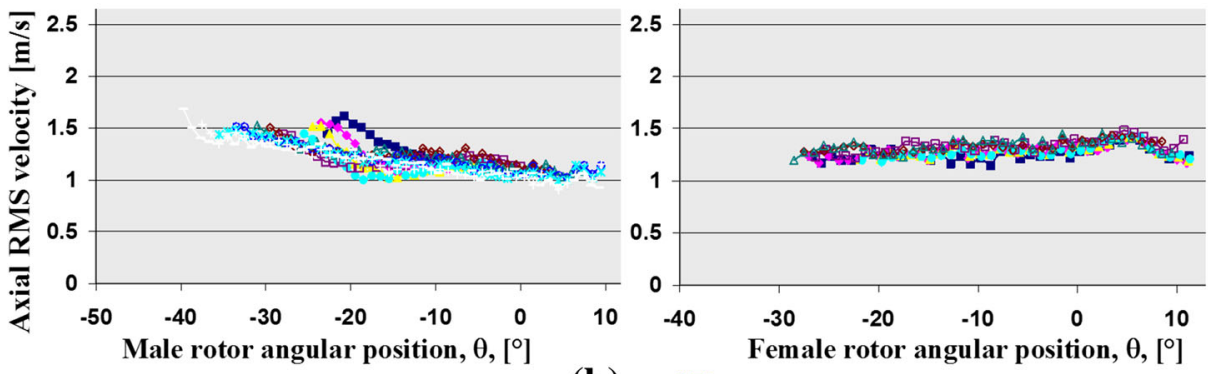

(b) $\alpha_{\mathrm{p}}=37^{\circ}$

Fig. 10 Axial RMS velocity distribution as a function of angular position, $\theta$, within the male (left column) and female (right column) rotors at different radial positions, $R_{p}$, and at $H_{p}=34 \mathrm{~mm}$ : (a) $\alpha_{p}=17^{\circ}$; (b) $\alpha_{p}=37^{\circ}$ 

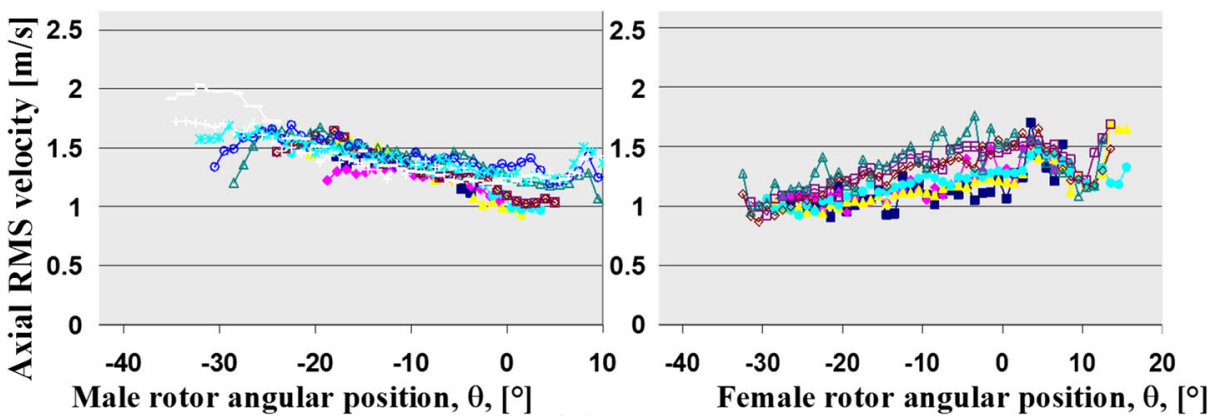

(a) $\alpha_{\mathrm{p}}=17^{\circ}$
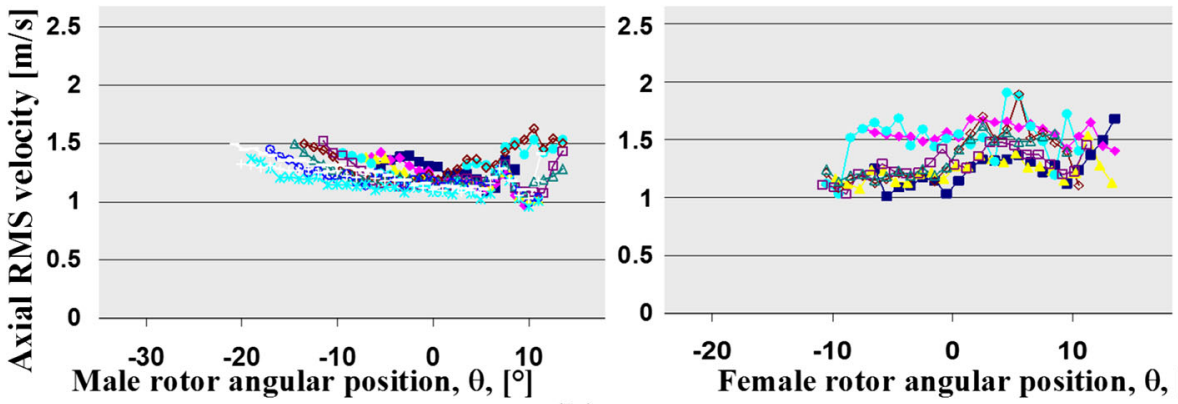

(b) $\alpha_{\mathrm{p}}=37^{\circ}$

Fig. 11 Axial RMS velocity distribution as a function of angular position, $\theta$, within the male (left column) and female (right column) rotors at different radial positions, $\mathrm{R}_{\mathrm{p}}$, and at $\mathrm{H}_{\mathrm{p}}=22 \mathrm{~mm}$ : (a) $\alpha_{\mathrm{p}}=17^{\circ}$; (b) $\alpha_{\mathrm{p}}=37^{\circ}$

where the whole flow is more exposed to the discharge port. The results show, unlike at $\mathrm{H}_{\mathrm{p}}=$ $22 \mathrm{~mm}$, the axial RMS velocities are less uniform with $\theta$ and higher fluctuation with $\mathrm{R}_{\mathrm{p}}$ than those observed in Fig. 10 further away from the port. This is expected as the larger mean flow variations were observed at this axial location as the flow is more exposed to discharge port. Despite these, the overall average RMS value at this axial station remain similar to that of $\mathrm{H}_{\mathrm{p}}=$ $34 \mathrm{~mm}$ with a value of around $0.3-0.35 \mathrm{~V}_{\mathrm{p}}$. It should also be noted that although the fluctuation of RMS velocity with $R_{p}$ is larger at this location, still there is no clear trend to indicate that the changes can be correlated to $\mathrm{R}_{\mathrm{p}}$. Again, the largest $\mathrm{RMS}$ velocity values are with the male rotor with the similar magnitude to those detected at $\mathrm{Hp}=34 \mathrm{~mm}$ near the LE and the rotor's tip within the flow of zone 3 associated with the tip flow leakage.

Figures 12 and 13 present the tangential RMS velocity distributions within the male and female working chambers at distances $34 \mathrm{~mm}$ and $22 \mathrm{~mm}$ from the discharge port, respectively. In general, the results show a similar trend to those observed with axial RMS velocity, but with larger fluctuations at different radial positions, and less uniform profiles with $\theta$. This behaviour is more pronounced within the male rotor chamber (left columns) due to lager variation of mean tangential flow velocities (Figs. 8 and 9) than those of the axial velocities (Figs. 6 and 7). In general, the RMS variations in all cases follow closely the mean tangential velocities with largest RMS values coincide with the steepest velocity gradient.

Again, there is no particular trend between the RMS angular velocity profiles within the male rotor (left column) working chamber with the radial positions, $\mathrm{R}_{\mathrm{p}}$, with overall values at around $1.75 \mathrm{~m} / \mathrm{s}\left(0.43 \mathrm{~V}_{\mathrm{p}}\right)$. However, with female rotor (right column), there is a clear correlation between the RMS variation and the radial positions, $R_{p}$, so that the RMS level is 

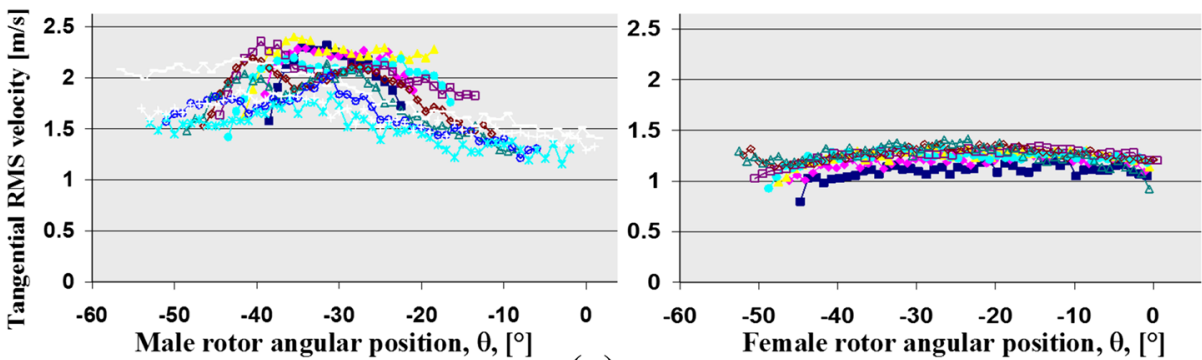

(a) $\alpha_{\mathrm{p}}=17^{\circ}$
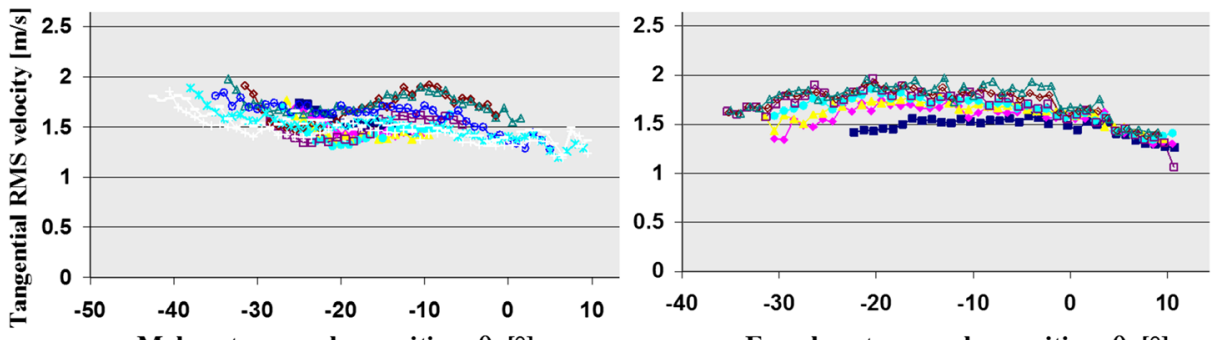

Male rotor angular position, $\theta,\left[^{\circ}\right]$

(b) $\alpha_{\mathrm{p}}=37^{\circ}$

Female rotor angular position, $\theta,\left[^{\circ}\right]$

Fig. 12 Tangential RMS velocity distribution as a function of angular position, $\theta$, within the male (left column) and female (right column) rotors at different radial positions, $\mathrm{R}_{\mathrm{p}}$, and at $\mathrm{H}_{\mathrm{p}}=34 \mathrm{~mm}$ : (a) $\alpha_{\mathrm{p}}=17^{\circ}$; (b) $\alpha_{\mathrm{p}}=37^{\circ}$
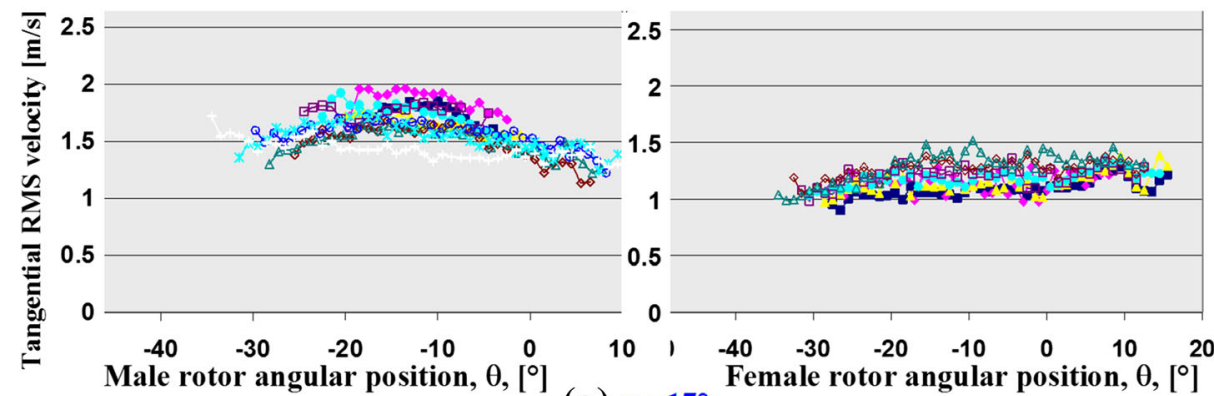

(a) $\alpha_{p}=17^{\circ}$
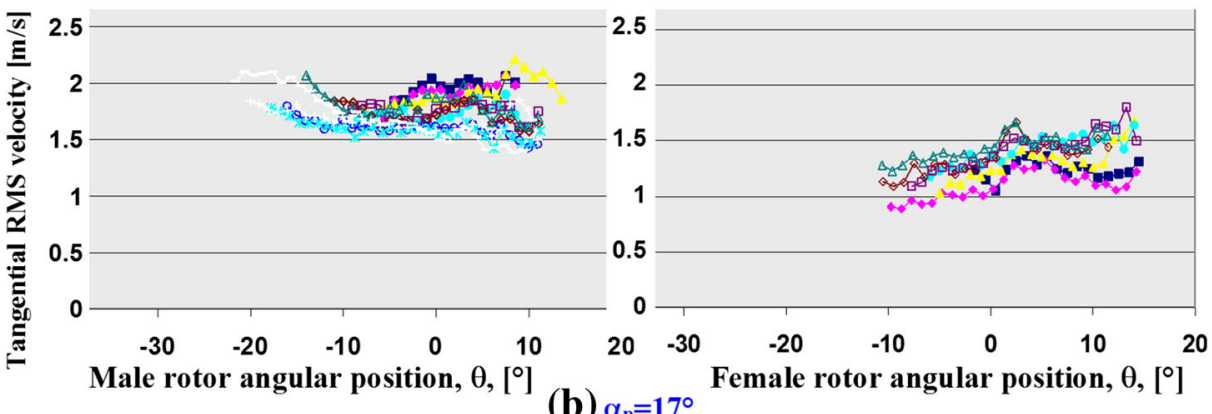

(b) $\alpha_{\mathrm{p}}=17^{\circ}$

Fig. 13 Tangential RMS velocity distribution as a function of angular position, $\theta$, within the male (left column) and female (right column) rotors at different radial positions, $\mathrm{R}_{\mathrm{p}}$, and at $\mathrm{H}_{\mathrm{p}}=22 \mathrm{~mm}$ : (a) $\alpha_{\mathrm{p}}=17^{\circ}$; (b) $\alpha_{\mathrm{p}}=37^{\circ}$ 
lowest at the root of the rotor and increases with $\mathrm{R}_{\mathrm{p}}$ to become largest near the tip of the rotor; the minimum and maximum values are of order of $1 \mathrm{~m} / \mathrm{s}\left(0.25 \mathrm{~V}_{\mathrm{p}}\right)$ and $1.75 \mathrm{~m} / \mathrm{s}\left(0.43 \mathrm{~V}_{\mathrm{p}}\right)$, respectively; similar range that was observed for axial components. Considering the overall RMS results of axial and tangential components for both rotors, it would be reasonable to assume the local turbulence to be isotropy for the modelling purposes.

\section{Conclusions}

Axial and tangential mean flow measurements and the corresponding turbulent velocity fluctuations were obtained inside the male and female working chambers of a double screw compressor at two axial locations $\left(\mathrm{H}_{\mathrm{p}}=22\right.$ and $\left.34 \mathrm{~mm}\right)$ upstream the discharge port, two radial planes of $\alpha_{p}=17^{\circ}$ and $37^{\circ}$, and different radial positions, $R_{p}$, from root to tip of the rotors. Cycle-resolved velocity measurements were made over a time window of $1^{\circ}(\Delta \theta)$ and at a rotor's speed of $1000 \mathrm{rpm}$ and outlet to inlet pressure ratio of 1:1 using a laser Doppler velocimetry (LDV) system. The followings are a summary of the most important findings:

1. The mean axial and tangential velocity distributions within the male and female working chambers confirmed the presence of two distinct flow zones 1 and 2 before and after the opening of the discharge port, $\theta=0^{\circ}$, controlled mainly by the rotor motion and the flow exposure into the discharge port, respectively. A third zone was also identified with male rotor only near the tip region, where the chamber flow is influenced greatly by the leakages through the gaps between the rotors and the casing.

2. In zone 1 at both radial planes, $\alpha_{\mathrm{p}}$, the axial mean flow within the male chamber was associated with an increase of velocity from the leading edge (LE) to a maximum value around the core region and then decreased towards port opening $\left(\Delta \theta=0^{\circ}\right)$, while the tangential mean flow showed an opposite flow pattern with a minimum value around the core region.

3. The largest changes in mean flow velocities were observed in zone 2, where a sudden increase in mean axial and tangential velocity components were obtained in the form of strong jet-like flows within both male and female working chambers due to opening of the discharge port and the exposure of the high-pressure flow into the discharge cavity; these flow features were more pronounced closer to the discharge port at $\mathrm{H}_{\mathrm{p}}=22 \mathrm{~mm}$.

4. RMS velocity distributions within the male and female working chambers were found to be uniform across the chamber with small differences at different $R_{p}$ and $\theta$; the differences were more pronounced closer to the discharge port at $\mathrm{H}_{\mathrm{p}}=22 \mathrm{~mm}$. Despite that, the overall average RMS value at both $\mathrm{H}_{\mathrm{p}}$ remained similar with values around $0.3 \mathrm{~V}_{\mathrm{p}}$ and $0.35 \mathrm{~V}_{\mathrm{p}}$ for axial and tangential flows, respectively.

5. Overall, the mean and turbulent results clearly showed the presence of a 3-D mean flow structure within the male and female chambers that became more complex as it moved closer to the discharge port. The similarity of the measured turbulent levels for both components and rotors suggested that it would be reasonable to assume the local turbulence to be isotropy for the modelling purposes.

6. The new measured data would be a unique contribution to literature, and have been obtained in great details to be used for the validation of CFD codes to establish a reliable model for accurate prediction of flow and pressure distribution within twin screw machines, which can then be used as a tool to further improve the design of screw compressors and expanders. 
Acknowledgement Financial support from EPSRC is gratefully acknowledged. The authors would like to thank Tom Fleming, Michael Smith, Jim Ford and Grant Clow for their valuable technical support during the course of this work.

Open Access This article is distributed under the terms of the Creative Commons Attribution 4.0 International License (http://creativecommons.org/licenses/by/4.0/), which permits unrestricted use, distribution, and reproduction in any medium, provided you give appropriate credit to the original author(s) and the source, provide a link to the Creative Commons license, and indicate if changes were made.

\section{References}

1. Stosic, N.: On gearing of helical screw compressor rotors. Proc IMechE. 213(C), 587-594 (1998)

2. Stosic, N.: Review article: screw compressors in refrigeration and air conditioning. HVAC and R Research. 10(3), 233-263 (2004)

3. Guerrato, D.: Cycle-Resolved flow Characterisitcs Within a Screw Compressor, Ph.D. Thesis, City, University of London, 2012

4. Nouri, J.M., Guerrato, D., Stosic N., Kovacevic, A.: Cycle-resolved velocity measurements within a screw compressor. $18^{\text {th }}$ Int. Compressor Eng. Conf., Purdue, USA, 17-20 July 2006

5. Guerrato, D., Nouri, J.M., Stosic, N., Arcoumanis, C.: Axial flow and pressure characteristics within a double screw compressor. $3^{\text {rd }}$ Int. Conf. Optical and Laser Diagnostics, ICOLD, London, 23-25 May 2007

6. Nouri, J.M., Guerrato, D., Stosic, N., Arcoumanis, C.: Axial flow characteristics within a screw compressor. ASHRAE Research Journal. 14(2), 259-274 (2008)

7. Guerrato, D., Nouri, J.M., Stosic, N., Arcoumanis, C., Smith, I.K.: Flow measurements in the discharge port of a screw compressor. Proceedings of the IMechE, Part E: Journal of Process Mechanical Engineering. 222(E4), 201-210 (2008)

8. Kovacevic, A., Stosic, N., Smith, I.K.: The CFD Analysis of a Screw Compressor Suction. Int. Compressor Eng. Conf., Purdue, USA 909 (2000)

9. Kovacevic, A., Stosic, N., Smith, I.K.: CFD analysis of screw compressor performance. In: Tourlidakis, A., Yates, M.K., Elder, R.L. (eds.) Advances of CFD in Fluid Machinery Design. Professional Engineering Publishing, London (2002)

10. Stosic, N., Mujic, E., Kovacevic, A. Smith, I.K.: The Influence of discharge ports on rotor contact in screw compressor. $18^{\text {th }}$ Int. Compressor Eng. Conf., Purdue, USA 17-20 July 2006

11. Sham, R., Kovacevic, A.: Algebraic generation of single domain computational grid for twin screw machines. Part I. Implementation. Advance in Engineering Software. 107, 38-55 (2017)

12. Bianchi, G., Sham, R., Kovacevic, A., Cipollone, R.: Deforming grid generation for numerical simulations of fluid dynamics in sliding vane rotary machines. Advance in Engineering Software. 112, 180 (191, 2017)

13. Yan, D., Kovacevic, A., Tang, Q., Sham, R., Zhang, W.: Numerical modelling of twin-screw pumps based on computational fluid dynamics. Proc IMechE Part C: J Mechanical Engineering Science. 231(24), 46174634 (2016)

14. Wu, H., Xing, Z., Shu, P.: Theoretical and experimental study on indicator diagram of twin screw refrigeration compressor. Int. Journal of Refrigeration. 27, 331-338 (2004)

15. Sauls J, Powell G, Weathers B.: Transient thermal analysis of screw compressors part I - development of thermal model. VDI Berichte, 19-29 (2006)

16. Hsieh, S.H., Shih, Y.C., Hsieh, W.H., Lin, F.Y., Tsai, M.J.: Performance analysis of screw compressors numerical simulation and experimental verification. Proc. IMechE part C, J. mechanical engineering. Science. 226, 968-980 (2012)

17. Kampanis, N., Arcoumanis, C., Kato, R., Kometani, S.: Flow, combustion and emissions in a five-valve research gasoline engine. SAE Paper 2001-013557, Ditroit, USA, 2001

18. Yan, Y., Gashi, S., Nouri, J.M., Lockett, R.L., Arcoumanis, C.: Investigation of Spray Characteristics in a Spray Guided DISI Engine Using PLIF and LDV, $2^{\text {nd }}$ Int. Conference on Optical Diagnostics, ICOLD, London, September 2005

19. Liu, C.H., Nouri, J.M., Vafidis, C., Whitelaw, J.W.: Experimental Study of Flow in a Centrifugal Pump, $5^{\text {th }}$ International Symposium on Applications of Laser Techniques to Fluid Mechanics, Lisbon, July 1990

20. Arcoumanis, C., Martinez-Botas, R., Nouri, J.M., Su, C.C.: Performance and exit flow characteristics of mixed flow turbines. International Journal of Rotating Machinery. 3(4), 277-293 (1997)

21. Arcoumanis, C., Martinez-Botas, R., Nouri, J.M., Su, C.C.: Inlet and exit flow characteristics of mixed flow turbines. ASME, Int. gas Turbine and Aeroengine Congress and Exhibition, Paper 98-GT-495, Stockholm, June 1998 
22. Zaidi, S.H., Elder, R.L.: Investigation of flow in a radial turbine using laser anemometry. ASME, Int. Gas Turbine and Aeroengine Congress and Exhibition, Cincinnati, paper 93-GT-55, Ohio, May 1993

23. Hockey, R.M., Nouri, J.M.: Turbulent flow in a baffled vessel strirred by a $70^{\circ}$ pitched blade impeller. Chem. Eng. Science. 51, 4405-4421 (1997) 